\title{
Desempenho agronômico de forrageiras tropicais
}

\author{
Agronomic performance of tropical forages \\ Rendimiento agronómico de las forrajes tropicales
}

Recebido: 13/10/2021 | Revisado: 20/10/2021 | Aceito: 21/10/2021 | Publicado: 24/10/2021

\author{
Renata Vilalba Reis \\ ORCID: https://orcid.org/0000-0002-8040-7841 \\ Universidade Federal do Mato Grosso, Brazil \\ E-mail: renata-vilalba@hotmail.com \\ Rosana Andréia Silva Rocha \\ ORCID: https://orcid.org/0000-0002-9072-3776 \\ Universidade Federal do Mato Grosso, Brazil \\ E-mail: rocharosana890@gmail.com. \\ Deborah de Amorim Teixeira Santos \\ ORCID: https://orcid.org/0000-0001-8036-424X \\ Universidade Federal do Mato Grosso, Brazil \\ E-mail: deborahamorim7@hotmail.com \\ Veridiana Camila Ferreira Búfalo \\ ORCID: https://orcid.org/0000-0001-7390-3954 \\ Universidade Federal do Mato Grosso, Brazil \\ E-mail: veribufalo@gmail.com
}

\begin{abstract}
Resumo
As gramíneas constituem a base da alimentação para bovinos de corte e leite, e devido a sua grande importância, é necessário escolher cultivares adaptadas a diversas condições edafoclimáticas, tendo em vista a ampla extensão territorial do Brasil. Dessa forma, objetivou-se com esse estudo, avaliar a produção bruta, produção de matéria verde, taxa de acúmulo e altura de planta de duas forrageiras tropicais. Para isso, foi conduzido um experimento a campo, em uma área de pastagem, localizado em uma propriedade no município de Nova Maringá, Estado de Mato Grosso. O experimento foi conduzido por delineamento experimental em blocos casualizados (DBC) com dois tratamentos, sendo: a cultivar Piatã (Urochloa brizantha) e a cultivar Zuri (Megathyrsus maximus) e 10 repetições, totalizando 20 parcelas. A unidade experimental, foi representada por uma área total de 0,7 ha. As variáveis avaliadas foram produção bruta, produção de matéria verde, taxa de acúmulo e altura de planta. A coleta dos dados foi realizada 100 dias após a emergência. A gramínea do gênero de Megathyrsus maximus cultivar Zuri, possuem grande potencial para a produtividade, e a cultivar Piatã, apresentou resultados não tão satisfatório. Porém, cada cultivar dispõem de características próprias, e se comporta de formas diferentes onde são cultivadas.
\end{abstract}

Palavras-chave: Forrageira; Urochloa brizantha; Megathyrsus maximus.

\begin{abstract}
Brazilian cattle breeding is based on the creation of beef animals and grazing milk, which demands a choice of cultivars adapted to different edaphoclimatic conditions, given the wide extent of Brazil. Thus, the objective of this study was to evaluate the gross production, production of green matter, accumulation rate and plant height of two tropical forages. For this, a field experiment was conducted, in a pasture area, located on a property in the municipality of Nova Maringá, State of Mato Grosso. The experiment was conducted by a randomized block design (DBC) with two treatments, namely: the cultivar Piatã (Urochloa brizantha) and the cultivar Zuri (Megathyrsus maximus) and 10 replicates, totaling 20 plots. The experimental unit was represented by a total area of 0.7 ha. The variables evaluated were gross production, production of green matter, rate of accumulation and plant height. Data collection was performed 100 days after the emergency. The grass of the genus Megathyrsus maximus cultivar Zuri, has great potential for productivity, and the cultivar Piatã, presented results not so satisfactory. However, each cultivar has its own characteristics, and behaves in different ways where they are cultivated.
\end{abstract}

Keywords: Forage; Urochloa brizantha; Megathyrsus maximus.

\section{Resumen}

Las gramíneas son la base de la alimentación del ganado vacuno y lechero, y debido a su gran importancia, es necesario elegir cultivares adaptados a diferentes condiciones edafoclimáticas, considerando la amplia extensión territorial de Brasil. Así, el objetivo de este estudio fue evaluar la producción bruta, producción de materia verde, tasa de acumulación y altura de planta de dos forrajes tropicales. Para ello, se realizó un experimento de campo, en una zona de pastos, ubicada en una propiedad en el municipio de Nova Maringá, Estado de Mato Grosso. El experimento se realizó en un diseño de bloques al azar (DBC) con dos tratamientos: el cultivar Piatã (Urochloa brizantha) y el cultivar Zuri 
(Megathyrsus maximus) y 10 repeticiones, totalizando 20 parcelas. La unidad experimental estuvo representada por un área total de 0,7 ha. Las variables evaluadas fueron producción bruta, producción de materia verde, tasa de acumulación y altura de planta. La recolección de datos se realizó 100 días después de la emergencia. La gramínea del género Megathyrsus maximus, cultivar Zuri, tiene un gran potencial de productividad, y el cultivar Piatã, mostró resultados menos satisfactorios. Sin embargo, cada cultivar tiene sus propias características y se comporta de diferentes formas donde se cultivan.

Palabras clave: Forraje; Urochloa brizantha; Megathyrsus maximus.

\section{Introdução}

A pecuária brasileira é um dos setores que vem se destacando na economia do país ao longo das últimas décadas. O Estado de Mato Grosso apresenta o maior rebanho de bovinos do pais, com mais de 24 milhões de cabeças de gado (IBGE, 2018). As gramíneas têm grande importância, pois constituem a base da alimentação da bovinocultura de corte e leite (Bulegon et al., 2013), além de ser a fonte alimentar de maior importancia para esses animais (Costa et al., 2009).

A escolha da forragem para a formação de uma pastagem deve ser rigorosamente avaliada, visando maior produção de biomassa, estabelecimento e equilíbrio estacional. A produção animal a pasto é a forma mais prática e de menor custo na alimentação (Duarte et al., 2016).

O estudo das adaptações de plantas aos diferentes modos de produção e condições do solo permite diferentes métodos de manutenções do manejo das pastagens. É importante entender e controlar os processos de crescimento e desenvolvimento que resultam na produção da forragem consumida. Há diversos tipos de cultivares no mercado, cada uma com diferentes potenciais de produção, no entanto, em diversas regiões os comportamentos das forragens são diferentes (Gomide et al., 2019).

A capacidade de produção da pastagem esta intrinsecamente relacionadas as condições de ambiente prevalecente na área e ás práticas de manejo adotadas, sendo assim, fatores como a temperatura, luminosidade, água e nutrientes condicionam o potencial fotossintético do dossel, em decorrência de alterações na área foliar e na capacidade fotossintética da planta. Essas variações de ambiente são responsáveis pela distribuição territorial das diferentes espécies de forrageiras e influenciam de maneira direta a produtividade das pastagens (Bauer et al., 2011; Anusckiewicz, 2016).

Cruz (2010) menciona que a capacidade de produção de uma forrageira é determinada pela sua genética. Sendo assim, a produtividade e a qualidade das pastagens são determinadas por um conjunto de fatores do meio, que agem sobre a produção mediante resposta de cada espécie forrageira a diferentes condições climáticas impostas pelo ambiente.

De acordo com Santos et al. (2018), as pastagens cultivadas em climas tropicais são de grande valor nutricional para a produção animal que é predominantemente realizada em sistemas produtivos à pasto. Porém o sucesso da implantação de uma determinada espécie em uma região depende do conhecimento das características genéticas da forrageira escolhida, que possam se adaptar melhor com a temperatura de cada região. Segundo Silva (2019), o crescimento da forrageira vária de acordo com o gênero da espécie cujas algumas necessitam de um manejo adequado, pois não exigem tanto do clima e seu desenvolvimento é influenciado pelo uso de nutrientes.

Para Silva et al. (2020), a cultivar Zuri, apresenta elevada produção e alto valor nutritivo, sendo plantas cespitosa de porte alto e ereto, com folhas verde escuras e arqueado. Já a cultivar Piatã, é uma forrageira com boa adaptação a solos de média a boa fertilidade e mal drenado, apresentando maior acúmulo de folhas que outras espécies do mesmo gênero. Contudo, o potencial de produção é obtido sob condições ideais, sendo que a genética da planta forrageira define o potencial produtivo, enquanto o manejo é responsável pela expressão dessa característica (Cabral \& Assis, 2019).

No Municipio de Nova Maringá, pouco se tem estudos sobre as características de gramíneas que são implantadas nessa região, assim estudos sobre os desempenhos de diferentes forrageiras possibilitara a melhor escolha para o cultivo, uma vez que, nos dias atuais o mercado está cada vez mais competitivo e buscando plantas forrageiras com alto potencial de produção. 
Portanto, objetivou-se com esse estudo, avaliar a produção de matéria verde, taxa de acúmulo e altura de planta de duas forrageiras tropicais na região de Nova Maringá, Estado de Mato Grosso.

\section{Materiais e Métodos}

O experimento foi conduzido em uma área de pastagem, localizado em uma propriedade no município de Nova Maringá, Estado de Mato Grosso, com uma latitude $12^{\circ} 51^{\prime} 47.137^{\prime}$ ' S, longitude 56 $45^{\prime} 17.447^{\prime \prime}$ W e 288,73 metros de altitude. Segundo a classificação de Köppen Am (clima tropical úmido ou sub-úmido), com precipitação anual de 147 mm, e temperatura variando de $18^{\circ} \mathrm{C}$ a $33^{\circ} \mathrm{C}$ ao longo do ano. $\mathrm{O}$ delineamento experimental utilizado foi em blocos casualizados (DBC) com dois tratamentos, sendo: a cultivar Piatã (Urochloa brizantha) e a cultivar Zuri (Megathyrsus maximus) e 10 repetições, totalizando 20 parcelas, com uma área total de 0,7 ha.

O solo foi coletado na camada de 0-20 cm cujas amostras foram submetidas a caracterização química e granulométrica do solo representada na Tabela 1 e determinada de acordo com Embrapa (1997).

Tabela 1 - Análise química e granulométrica na profundidade de 0-20 cm.

\begin{tabular}{rrrrrrrrrrrrrrr}
\hline $\mathrm{pH}$ & $\mathrm{K}$ & $\mathrm{P}$ & $\mathrm{Ca}$ & $\mathrm{Mg}$ & $\mathrm{Al}$ & $\mathrm{H}$ & $\mathrm{H}+\mathrm{Al}$ & $\mathrm{CTC}$ & $\mathrm{SB}$ & $\mathrm{V} \%$ & $\mathrm{M} . \mathrm{O}$ & Areia & Silte & Argila \\
\hline $\mathrm{CaCl}_{2}$ & \multicolumn{2}{c}{$\mathrm{mg} / \mathrm{dm}^{3}$} & & & & $\mathrm{cmolc} / \mathrm{dm}^{3}$ & & & $\%$ & & $\mathrm{~g} / \mathrm{dm}^{3}$ & & $\mathrm{~g} / \mathrm{kg}$ & \\
\hline 6,60 & 14,4 & 2,20 & 0,8 & 0,44 & 0,12 & 4,58 & 4,70 & 6,16 & 1,46 & 27,70 & 16,38 & 599,6 & 53,1 & 47,3 \\
\hline
\end{tabular}

Fonte: Autores (2021).

De acordo com os resultados da análise do solo e recomendações de Sousa e Lobato (2004) realizou-se a correção e adubação do solo, onde foi aplicado 2,630 t/ha de calcário, e incorporado ao solo por meio de gradagem. Para a adubação foram utilizados a ureia com doses de 233,33kg/ha, superfosfato simples 388,88 kg/ha e cloreto de potássio 46,66 kg/ha. A semeadura ocorreu em novembro de 2019, onde as sementes foram semeadas manualmente, a três cm de profundidade, totalizando $5 \mathrm{~kg}$ de sementes em cada tratamento e o controle de pragas e doenças foi realizado conforme o monitoramento diário da área.

Em fevereiro de 2020, 100 dias após a emergência ocorreu à coleta dos dados. Para as avalições foi utilizado o método do quadrado de acordo com a EMBRAPA (2006). Onde para determinar a massa verde, utilizou-se uma armação de metal, com as medidas de $0,5 \times 0,5 \mathrm{~m}$, totalizando $0,25 \mathrm{~m}^{2}$. Essa armação foi jogada aleatoriamente uma vez em cada parcela e todas as plantas contidas no seu interior foram cortadas com auxílio de cutelo e acondicionadas em sacos de papel identificados e pesado em uma balança digital. Os dados obtidos foram transformados em $\mathrm{kg} / \mathrm{ha}$.

Para determinar a altura de planta utilizou-se uma fita métrica, sendo realizadas três leituras para obter-se a média para cada parcela. Foi medido do solo até o perfilho, com a folha completamente expandida (Wasselai et al., 2020).

Os dados obtidos foram submetidos a análise de variância e as médias dos tratamentos foram comparadas pelo Teste de Tukey, ao nível de 5\% de significância, utilizando o programa estatístico SISVAR (Ferreira, 2008).

\section{Resultados e Discussões}

Os resultados obtidos no presente estudo, apresentaram diferença significativa para as variáveis estudadas, onde a cultivar Zuri foi a que apresentou maiores incrementos para a produção em relação a cultivar Piatã. Essa diferença pode ser justificada, pela maior participação da fração colmo em razão da vedação da pastagem, para essa forrageira, e devido seu alto poder de crescer lançando novos brotos ou caule de maneira aglomerada (Silva, 2019). 
O desempenho da produção de matéria verde entre as cultivares estudadas estão ligados a diversos fatores. Segundo Tomaz (2017), a maior produção de folhas das forrageiras é influenciada por características genéticas, nutrição, manejo adequado, condução dos cortes e características climáticas. Assim corroborando com os dados analisados no presente estudo, a cultivar Zuri, apresentou produção superior, em relação a cultivar Piatã, isso pode ser explicado devida suas características em se adaptar bem em diversas condições (Tabela 2).

Tabela 2 - Produção bruta de massa verde $\left(\mathrm{m}^{2}\right)$, produção de matéria verde (ha), taxa de acúmulo (kg/ha/dia) e altura de planta (m).

\begin{tabular}{ccccc}
\hline Tratamento & $\begin{array}{c}\text { Produção Bruta de } \\
\text { massa verde }\left(\mathbf{m}^{\mathbf{2}}\right)\end{array}$ & $\begin{array}{c}\text { Produção de } \\
\text { massa verde }(\mathbf{h a})\end{array}$ & $\begin{array}{c}\text { Taxa de acúmulo } \\
(\mathbf{k g} / \mathbf{h a} / \mathbf{d i a})\end{array}$ & $\begin{array}{c}\text { Altura de } \\
\mathbf{p l a n t a}(\mathbf{m})\end{array}$ \\
\cline { 2 - 5 } & $1,295 \mathrm{a}$ & $12950 \mathrm{a}$ & $129,5 \mathrm{a}$ & $2,35 \mathrm{a}$ \\
Puri & $1,095 \mathrm{~b}$ & $10950 \mathrm{~b}$ & $109,5 \mathrm{~b}$ & $2,17 \mathrm{~b}$ \\
\hline
\end{tabular}

Médias seguidas de mesma letra minúsculas nas linhas não diferem estatisticamente entre si ao nível de 5\% de probabilidade pelo teste de Tukey.

Fonte: Autores (2021).

Almeida (2015), ressalta que algumas espécies de forrageiras tropicais, particularmente aquelas de crescimento cespitoso, como no caso do capim Zuri o alongamento dos colmos é um dos componentes importantes para o crescimento e que interfere consideravelmente na estrutura do pasto. Reafirmando assim os resultados vistos em estudo.

Segundo Santos et al. (2018), verificou em seus estudos que o déficit hídrico e menor luminosidade refletem diretamente na taxa fotossintética da planta, logo, contribuem para o menor crescimento da matéria verde das forrageiras. Comportamento não observado no experimento estudado, haja visto, que os dois tratamentos foram submetidos aos mesmos manejos durante o experimento, mesma intensidade de luz e precipitação, apesar disso, houve diferença entre os tratamentos.

No estudo de Rocha (2016), avaliando a taxa de aparecimento de folhas, com diferentes cultivares e época de avaliação, foi observado que as cultivares Massai, Mombaça e Piatã não apresentaram, diferença entre o período de seca e de água. Do mesmo modo Bulegon et al. (2013) estudando características morfogênicas de quatro espécies de gramíneas forrageiras tropicais, sob diferentes condições hídricas do solo, salientam o aumento na taxa de aparecimento de folhas em função da maior disponibilidade de água no solo.

Para Valote (2018) a maior taxa de alongamento foliar em forrageiras está associada a característica atribuída a genótipos produtivos, mesmo quando estão sob mesmas condições de manejo. Explicando assim, os resultados obtivo no presente estudo. Segundo Gomide et al. (2019) o acúmulo de forragem durante o período de crescimento e rebroto das plantas após pastejo é determinante da quantidade e qualidade da massa produzida. Embora no presente estudo não houve presença de animais para pastejo, no entanto, a cultivar Zuri apresentou um incremento de $129,5 \mathrm{~kg} / \mathrm{ha} /$ dia, em relação a cultivar Piatã (Tabela 2).

De acordo com Porto (2017), estudando a distribuição estacional da produção anual de acúmulo de forragem do gênero Urochloa e Megathyrsus, verificaram que não diferiram entre si e apresentaram maior produção em torno de $63 \%$ no período chuvoso e $37 \%$ no período seco. Nas outras regiões do Brasil, cerda de 60 a $80 \%$ da produção de forragem se concentra no período das chuvas (Silva et al., 2020).

Estes resultados comprovam que a maioria das forrageiras tem uma grande dependência dos fatores climáticos e das características genética, para alavancar a produção. Cruz (2010), ressalta que onde não há fatores climáticos limitantes a produção de gramíneas é bastante responsiva. 
De acordo com Kirchner et al. (2020), com o aumento do diâmetro de colmos, maior será a altura total da planta, e assim, maior será o total de massa produzida, além disso, o diâmetro de colmos em espécies forrageiras possui grande importância pelo fato de que os animais os ingerem. Evidenciando com o estudo analisado, onde foi visto que a cultivar que obteve maior massa produzida, foi a que apresentou maior altura de planta, no entanto não foi analisado diâmetro de colmo (Tabela 2).

Estudo realizado com forrageiras comprovaram a alta relação entre a interceptação luminosa a altura das plantas, independente da época do ano e do estádio fisiológico das plantas, apontando que na prática a altura pode ser utilizada como critério para as tomadas de decisão no manejo do pasto (Dias-Filho, 2015).

De acordo com Kirchner et al. (2020) a altura apresenta diferença, quanto a espécies e cultivares, sendo influenciada por fatores como genótipo da planta, balanço hormonal, estádio de desenvolvimento, fotoperíodo, temperatura, luminosidade e disponibilidade de água e nutrientes, sendo o primeiro o que mais influência. No presente estudo houve diferença entre as cultivares em relação à altura de planta (Tabela 2). Desde modo, a altura apresenta uma relação direta com a massa de forragem quando o manejo é baseado nas características fisiológicas da planta (Bulegon et al., 2013).

\section{Conclusões}

A gramínea do gênero de Megathyrsus maximus cultivar Zuri, possui grande potencial para a produtividade, por apresentar boa produção de massa verde, taxa de acúmulo e altura de planta.

A cultivar Piatã, foi a que apresentou menores incrementos para as variáveis analisadas, obtendo menor produção. Entretanto, cada cultivar dispõem de características próprias, e se comporta de formas diferentes em relação ao meio em que está inserido. Assim a melhor forrageira a partir do estudo realizado foi a cultivar Zuri, apresentando grande potencial de produção, sendo assim uma ótima opção para a produção de forragem.

Para trabalhos futuros, sugerimos que se faça com mais de duas forrageiras, assim possibilitaria evidênciar os efeitos de diferentes cultivar em uma determinada região especifica.

\section{Referências}

Almeida, O. G. (2015). Morfogênese e produção de acessos de Panicum maximum. International Journal of Soil Science, 10(1), 1-31.

Anusckiewicz, E. R. (2016). Gramíneas do gênero brachiaria. Departamento de zootecnia. Universidade Estadual Paulista.

Bulegon, L. G. et al. (2013). Características produtivas, estruturais e nutritivas de gramíneas tropicais sob pastejo. Colloquium Agrariare, 9(2), 1-15.

Cabral, C. H. A \& Assis, L. M. B. (2019). Investigating the Optimal Day for Nitrogen Fertilization on Piatã palisadegrass and Quênia guineagrass after Defoliation. Journal of Experimental Agriculture International, 34(6), 1-11.

Costa, K. A. P. et al. (2009). Produção de massa seca e nutrição nitrogenada de cultivares de Brachiaria brizantha sob doses de nitrogênio. Ciência e Agrotecnologia, 33 (6), 1578- 1585.

Cruz, P. G. (2010). Produção de forragem em Brachiaria brizantha: adaptação geração e avaliação de modelos empíricos e mecanicistas para estimativa do acúmulo de forragem. 102p. Tese (Doutorado) -Escola Superior de Agricultura Luiz de Queiroz, Piracicaba.

Dias-Filho, M. B. (2015).3 Diagnóstico das Pastagens no Brasil. Embrapa Amazônia 13 Oriental, 1-38, 2014. EMBRAPA. Qualidade da carne.

Duarte, C. F. D. et al. (2016). Capim-piatã adubado com diferentes fontes de fósforo. Revista Investigação, 15 (4), 58-63.

EMBRAPA - Empresa brasileira de pesquisa agropecuária. Manual de métodos de análises de solo. (1997). Centro Nacional de Levantamento e Conservação do Solo. Rio de Janeiro: Embrapa Solos. p. 212.

EMBRAPA - Métodos de amostragem para avaliação quantitativa de pastagens. (2006). Circular técnica. Porto Velho - RO. p. 06.

Ferreira, D. F. (2008). SISVAR: um programa para análises e ensino de estatística. Revista Symposium, 6(2), 36-41.

Gomide, C. A. M. et al. (2019). Productive and morphophysiological responses of Panicum maximum Jacq. cv. BRS Zuri to timing and doses of nitrogen application and defoliation intensity. Grassland Science, 1(8), 93-100.

IBGE - INSTITUTO BRASILEIRO DE GEOGRAFIA E ESTATÍSTICA. Resultado Preliminares do Censo Agro 2017. (2021). https://censos.ibge.gov.br/agro/2017/resultados-censo-agro-2017.html. 
Research, Society and Development, v. 10, n. 14, e37101421735, 2021

(CC BY 4.0) | ISSN 2525-3409 | DOI: http://dx.doi.org/10.33448/rsd-v10i14.21735

Kirchner, J. H. et al. (2020). Altura de plantas e diâmetros de colmos de sorgo forrageiro irrigado em função de cortes. Irriga, 25(2), $223-233$.

Matheus, R. A. (2016). Gramíneas no cerrado brasileiro: uma história ambiental das transformações das paisagens em goiás a partir do século XIX. Universidade estadual de Goiás, Dissertação apresentada ao Programa de Pós-Graduação TECCER. (Dissertação de Mestrado).

Rocha, F. (2016). Produção e nutrição do Panicum maximum BRS Zuri submetido a tipos de uréia. Cuiabá-MT. Tese (Doutorado) - Universidade Federal de Mato Grosso, Faculdade de Agronomia e Medicina Veterinária, Programa de Pós-Graduação em Agricultura Tropical.

Santos, M. E. R. et al. Escolha da espécie forrageira. Soesp/semnetes oeste paulista, 1, 1-5.

Silva, C. T. R. (2019). Cultivares de Urochloa brizantha submetidas a disponibilidades hídricas do solo. Rondonópolis-MT: Dissertação (Mestrado) Universidade Federal de Mato Grosso, Instituto de Ciências Agrárias e Tecnológicas, Programa de Pós-Graduação em Engenharia Agrícola e Ambiental.

Silva, E. B. et al. (2020). Chemical composition of Panicum maximum 'BRS Zuri' subjected to levels of salinity and irrigation depths. Revista Ciência Agronômica, 51(1), 1-10.

Sousa, D. M. G \& Lobato, E. (2004). Cerrado: correção do solo e adubação. (2a ed.), Embrapa Informação Tecnológica, p. 416.

Tomaz, P. K. (2017). Altura de planta como estratégia de colheita do capim mombaça para ensilagem associada ou não a diferentes combinações de aditivos. Dissertação (mestrado) - Universidade Estadual Paulista. Faculdade de Engenharia de Ilha. Área de conhecimento: Ciência e Tecnologia Animal. Ilha Solteira, SP.

Valote, P. D. (2018). Acúmulo de forragem e estrutura dos pastos das cultivares BRS Zuri e BRS Quênia (Megathyrsus maximus) sob manejo rotacionado. Seropédica-RJ: Disseertação (Mestrado) - Universidade Federal Rural do Rio de Janeiro, Zootecnia.

Wasselai, J. H. T. et al. (2020). Produção de forragem e características agronômicas de capim-piatã sob doses de nitrogênio. Bol. Ind. Anim., 77. 